\title{
A ORGANIZAÇÃO DO TRABALHO DIDÁTICO NA PROPOSTA DA ESCOLA PARQUE DE ANÍSIO TEIXEIRA
}

\author{
Enilda Fernandes ${ }^{1}$ \\ Paulo Edyr Bueno de Camargo ${ }^{2}$
}

\section{RESUMO}

Este texto apresenta resultados parciais de investigação coletiva financiada pelo Conselho Nacional de Pesquisa (CNPq) denominada: "A Organização do Trabalho didático na perspectiva dos educadores da Escola Nova (1930-1970)". A discussão elege a perspectiva histórica marxista tendo por referência a categoria Organização do Trabalho Didático. Tomou-se para estudo a proposta educacional de Anísio Teixeira, o Centro Carneiro Ribeiro (CCR), com o foco na Escola-parque. O Centro tem a sua organização dividida em dois espaços escolares distintos: as escolas-classe e as escolas-parque. Em um primeiro turno, os alunos têm aulas nas escolas-classe, com a oferta das matérias, comumente escolares. No turno subsequente, nas escolas-parque, são ofertadas a educação física, musical, saúde, artes industriais, etc. Anísio Teixeira, nos limites da concepção democrática burguesa, corrobora os pressupostos comenianos embasados nos conhecimentos básicos, generalistas e úteis, sem os aprofundamentos que propiciariam aos estudantes realizar uma crítica radical e de conjunto à sociedade capitalista. Ele se distingue da escola liberal comeniana pela organização do trabalho didático proposta em espaços físicos diferentes e pelo oferecimento de ensino em tempo integral.

Palavras-chave: Anísio Teixeira; Escola Nova; Escola-parque; Escola-classe.

\section{THE ORGANIZATION OF THE TEACHING WORK IN THE PROPOSAL OF DE THE SCHOOL-PARK OF ANÍSIO TEIXEIRA}

\begin{abstract}
The present text shows partial results of the collective research funded by the Brazilian Research Council (CNPq) entitled: "A Organização do Trabalho didático na perspectiva dos educadores da Escola Nova (1930-1970)" (The Organization of the teaching Work in the perspective of the teachers of the New School). The discussion adopts the historical Marxist perspective and has as reference the category Organization of the Teaching Work. The educational proposal of Anísio Teixeira, O Centro Carneiro Ribeiro (CCR) has been taken to study focusing on Escola-parque. This center has its organization divided into two schooling environments: the escolas-classe and the escolas-parque. In a first shift, the students have classes offering typical school subjects. In the following shift, in the escolasparque, it is offered to the students physical education, music, health, industrial arts, etc. Anísio Teixeira, within the limits of the bourgeois democratic, supports the "comenianos" pedagogy assumptions on the basic, generic and useful knowledge without the further deepening, which would allow the students to perform a radical and comprehensive criticism to the capitalist society. It distinguishes from the "escola liberal comeniana" because of the organization of the teaching work proposed in different physical places and by the offering of full time teaching.
\end{abstract}

Keywords: Anísio Teixeira; New School; Escola-parque; Escola-classe. 


\section{Introdução}

O texto que ora se apresenta consiste de resultados parciais de uma investigação coletiva, em andamento, financiada pelo Conselho Nacional de Pesquisa (CNPq), denominada: A Organização do Trabalho didático na perspectiva dos educadores da Escola Nova (1930-1970).

Tomou-se para análise a proposta educacional de Anísio Teixeira, com o foco no Centro Educacional Carneiro Ribeiro (CECR), sendo a sua organização dividida em dois espaços escolares distintos: escola-classes e escolas-parque, para a ampliação do tempo escolar. Em um primeiro turno, os alunos teriam aulas nas escolas-classe, onde seriam ofertados o ensino das matérias, comumente escolares, das seguintes áreas: Matemática, Línguas, Ciências, História e Geografia. No turno subsequente, nas escolas- parque, haveriam aulas de educação física, musical, sanitária, pelo uso das leituras e pela assistência alimentar.

A perspectiva educacional de Anísio Teixeira visava ao atendimento de um conjunto de necessidades não restritas apenas à formação intelectual, por meio das matérias das áreas especializadas comuns, mas também às necessidades ligadas aos aspectos éticos, estéticos e físicos. Cabe esclarecer que com vistas a formação integral do homem, Anísio Teixeira optou pela denominação "Centro Educacional" para distinguir do nome "escola" que tradicionalmente remete, de modo exclusivo à formação intelectual.

É relevante o estudo do educador Anísio Teixeira (1900-1971). Ele iniciou sua vida profissional com apenas 24 anos, assumindo o cargo de Inspetor Geral de Ensino, em Salvador, momento em que se engajou, na luta em defesa da escola pública, especialmente da escola primária. Foi em seu tempo, o grande reformador na história de educação brasileira. Signatário do Manifesto da Educação Nova de 1932, formulado à luz do liberalismo pragmático do filósofo John Dewey, Anísio propôs políticas educacionais, embasadas nos postulados filosóficos desse norte-americano, adaptando-as ao contexto político econômico brasileiro, marcado pelas pressões das diversas frações da classe burguesa, como assinala Santos (2006) em sua tese de doutorado.

O educador e estadista brasileiro concebendo que a educação deveria ser em tempo integral, criou em 1949, no bairro da Liberdade em Salvador, estado da Bahia, a primeira unidade da Escola-parque do Centro Carneiro Ribeiro, inaugurada em 1950, e que se encontra em funcionamento até os dias de hoje ${ }^{3}$. De acordo com Anísio (1971), tal proposta subverteria a simplificação destrutiva e a escola improvisada que reduzem a educação a poucas horas de instrução para aprender a ler, escrever e contar. No entanto, a despeito de reconhecer a significativa contribuição deste educador, é preciso assinalar os limites e as contradições de suas propostas educacionais, considerando a importância de seu empreendimento na reconstrução da educação brasileira no pós Segunda Guerra Mundial.

A análise realizada a partir da categoria "Organização do Trabalho Didático", referencia o estudo pela perspectiva histórica marxista. Essa categoria foi formulada por Alves $(2001,2005)$ após releitura da Didática Magna de João Amós Coménio - o articulador da proposta de educação moderna no século XVII ${ }^{4}$ - em contraposição à educação instituída na sociedade feudal. Para o educador morávio, o método manufatureiro de trabalho daria as bases materiais à universalização do ensino.

Não se pode prescindir de apreender o pensamento educacional de Anísio Teixeira no seu ser temporal-histórico, portanto, em absoluto, lhe será negado o mérito de seus incansáveis empreendimentos educacionais. Contudo, o foco primordial deve recair nos contornos burgueses conformados na perspectiva liberal. Procura-se, assim, identificar nos elementos da organização do trabalho didático: relação educativa, instrumentos de trabalho, 
métodos e processos de ensino, a presença do humanismo-pragmático do liberalismo clássico. Entende-se que apesar dos inúmeros estudos a respeito de Anísio Teixeira, não contam das discussões, aspectos que expressam no trabalho didático o pensamento humanista-pragmatista.

Este texto compõe-se de três partes fundamentais: na primeira parte, uma breve exposição biográfica de Anísio Teixeira e o seu projeto liberal-democrático. Na segunda parte, aborda-se a gênese da escola-parque e por fim, a organização do trabalho didático da Escola-parque do Centro Educacional Carneiro Ribeiro.

\section{Biografia de Anísio Teixeira: Um pouco de sua vida na História da Educação}

Anísio Espínola Teixeira (1900-1971), nascido na cidade de Caetité (BA), tornou-se um educador brasileiro reconhecido internacionalmente. A historiografia distingue $\mathrm{o}$ intelectual e sua ação, conferindo uma excepcionalidade à sua admirável disposição para os debates no campo educacional.

Há muitos escritos biográficos ${ }^{5}$ sobre esse educador, seja com produções específicas para abordar seus feitos e sua trajetória, ou produções que discutem sobre seu pensamento filosófico, político, social e educacional. Aqui, serão expostos apenas alguns aspectos marcantes de suas contribuições.

Anísio Teixeira realizou seus estudos primários e secundários nos colégios jesuíticos, Instituto São Luís Gonzaga, em Caetité, e Colégio Antônio Vieira, em Salvador, diplomando-se Bacharel em Direito na Universidade do Rio de Janeiro, em 1922. Iniciou sua carreira profissional em 1924, quando de volta a Salvador, a convite de Otávio Mangabeira, assumiu o cargo de Inspetor Geral do Ensino Estadual, até 1929. Nesta ocasião, realizou as primeiras leituras mais aprofundadas sobre a educação e impressionou-se com o livro Méthodes Américaines d'Éducation Générale et Technique (1908), de Omer Buyse. Foi, também, nessa ocasião que tomou conhecimento mais aprofundado do ensino na Bahia e publica o artigo: A propósito da Escola Única ${ }^{6}$, no qual faz uma apreciação de um livro de Carneiro Leão sobre a educação nacional, no qual aspira a universalização da "escola única". Teixeira (1924) concorda e escreve: "Uma 'escola única' obrigatória para todos, ministrando ensino de um modo integral e uniforme, seria o apparelho magico destinado a dar a todos os homens o pleno desenvolvimento de suas faculdades ${ }^{7}$ " . Indica, porém, a inexequibilidade do projeto do educador, que movido por seu idologismo despreza elementos triviais da complexa realidade humana.

Em 1925, já Inspetor do Ensino na Bahia, ausentou-se do Brasil por um período de quatro meses para uma viagem à Europa, onde observou escolas da Espanha, Bélgica, Itália e França, registrando suas impressões dos sistemas escolares daqueles países. Por ocasião de seu retorno concede uma entrevista ao jornal "A Tarde" . Ainda em 1925 transforma seu projeto de reforma do ensino da Bahia na Lei - $\mathrm{n}^{\circ}$ 1846, de 14/08/1925 - e apresentou ao governo Góes Calmon o relatório anual ${ }^{9}$ com a concepção de que a escola deveria oferecer o ensino em tempo integral.

Nos anos de 1927 e 1929, Anísio Teixeira esteve nos Estados Unidos da América. Foi na primeira viagem (1927) que teve contato com o pensamento de John Dewey e também de William H. Kilpatrick, dos quais tivera influência na primeira metade do século XX, Dewey, no entanto, passou a ser a sua referência principal para alicerçar as diretrizes que renovariam as bases da educação brasileira. Antes disso, porém, seu contato com a cultura norte-americana por meio do livro de Omer Buyse, motivou-lhe as primeiras revisões acerca de suas convicções educacionais, até então abalizadas pela ortodoxia católica, pois ele fora estudante do colégio jesuíta, informa Carvalho (2000). 
Sua viagem de 1927 de junho a novembro, oportunidade em que visitou diversos estabelecimentos de ensino em vários locais do país, como também excursionou por algumas organizações centrais de educação, fez observações e estudou sobre o funcionamento no campo da administração e finanças, organização escolar, cursos, métodos de ensino, programas, plano de organização, de cada uma das escolas e instituições visitadas, conforme se pode verificar no livro Aspectos Americanos da Educação (2006). Em suas reuniões e visitas às escolas, cujo foco seria a organização escolar norte-americana, Anísio Teixeira procurou evidenciar as condições materiais e intelectuais daquelas escolas e pontuou em seu relatório cada traço observado em sua organização didática e técnico-administrativafinanceira.

Naquela ocasião constatou a diferença entre os norte-americanos e latino americanos, em relação a estrutura socioeconômica e a presença marcante do desenvolvimento tecnológico na vida social e material daquele país, conforme pontua Santos (2006). O educador baiano, impactado, deixa claro que a resolução dos problemas, estaria organicamente constituída na técnica científica, pois, "a ciência experimental na sua aplicação às coisas humanas permitiu que uma série de problemas fossem resolvidos e que crescessem essas enormes cidades que são a flor e o triunfo da maior civilização" (TEIXEIRA, 1930, p. 9 apud SANTOS, 2006, p. 21). Além disso, Anísio Teixeira também se declarou profundamente marcado por John Dewey, tanto que em 1934, lançou o livro Em marcha para a democracia: à margem dos Estados Unidos, onde mostra o quanto os Estados Unidos lhe chamaram a atenção a respeito das condições materiais e culturais, pois "em nenhuma outra parte do mundo, a filosofia que governa as atitudes do homem diante da vida fornece condições para uma total renovação moral e cultural da sociedade que a nova ordem científica estaria a exigir $[\ldots . .$. ".

Entre 1928 e 1929 retornou à América para o curso de pós-graduação no Teachers College Columbia University, sendo sua tese o relatório Aspectos Americanos de Educação, cujas anotações foram coletadas oportunamente em suas visitas e excursões realizadas em 1927 e apresentadas ao governo da Bahia. Além disso, participou de cursos, disciplinas e pesquisas nas áreas de psicologia, filosofia, administração escolar, educação rural e didática, informa Santos (2006). Essa segunda viagem aos Estados Unidos foi oportuna e veio legitimar as suas revisões educacionais, bem como fortaleceu em busca de inspiração de caminhos que orientassem para reforma e a organização das instituições escolares brasileiras, por ocasião de sua gestão como diretor a Instrução Pública em Salvador. Suas reflexões sobre o conceito moderno de educação foram profundamente marcadas pelo pensamento de Dewey, nas suas palavras:

John Dewey é, na América, o filósofo que mais agudamente traçou as teorias fundamentais da educação americana. A nenhum outro pensador é dado ali um lugar tão saliente na sistematização da teoria moderna de educação (TEIXEIRA, 2006, p. 30).

De volta ao Brasil, Anísio realizou o balanço da instrução na Bahia de 1924 a 1929, apresentando ao governo suas propostas, as quais foram recusadas. Com isso, Anísio Teixeira demitiu-se, passando a dedicar-se ao Magistério, assumindo na Escola Normal de Salvador a cadeira de Filosofia e História da Educação.

De 1931 a 1935, destacam-se trabalhos de maior alcance realizados na capital da República. Na função de Secretário de Educação do Distrito Federal, na administração do Prefeito Pedro Ernesto, transformou a antiga Escola Normal, em Instituto de Educação e criou a rede municipal de ensino e a Universidade do Distrito Federal em 1935. No final 
desse mesmo ano, acusado de fazer parte do Levante Comunista, Teixeira pediu demissão do cargo de diretor de Instrução Pública do Distrito Federal e enviou ao prefeito Pedro Ernesto uma carta justificando sua decisão, na qual deixa claro não nutrir simpatia pela revolução comunista, conforme ilustra o seguinte fragmento:

\begin{abstract}
Renovo a declaração, porque não é possível aceitar agora a minha exoneração sem a ressalva de que ela não envolve, de modo algum, a confissão, que se poderia supor implícita, de participação, por qualquer modo, nos últimos movimentos de insurreição ocorridos no país. [...]. Lavro contra tal suspeição o meu protesto mais veemente, parecendo-me que tem ela mais largo alcance que a minha pessoa, porque importaria em não se reconhecer que progredir por educação é exatamente o modo adequado de se evitarem as revoluçõe $e^{10}[\ldots]$.
\end{abstract}

Na sequência, exilou-se no sertão da Bahia, região de Caetité, fazenda Gurutuba. Em 1930 reuniu dois ensaios de John Dewey - primeira tradução que fez da obra desse filósofo - e publicou o livro Vida e Educação no qual discute a relação entre os elementos do processo educativo e as matérias de estudo. E ainda neste mesmo ano Anísio Teixeira sintetiza o significado de suas viagens aos Estados Unidos no artigo: Por que Escola nova?

No período de 1937 a 1945, na Bahia, dedicou-se à exploração e exportação de manganês, calcário, cimento, comercializou automóveis, traduziu livros para a Companhia Editora Nacional (CEN) e, com o afastamento da vida pública, a correspondência com os amigos mantém viva a interlocução acerca dos problemas educacionais. Em 1946 exerce o cargo de Conselheiro de Ensino Superior da United Nations Educational \& Cultural Organization (Unesco) e no ano seguinte, a convite do recém-eleito Governador da Bahia Otávio Mangabeira (1947-1951) retornou à vida públicou e deu continuidade à sua luta pela educação popular. Além de outras atividades nesse período criou em 1949 em Salvador, no bairro da Liberdade, o Centro Carneiro Ribeiro, constituído para desenvolver a educação escolar em tempo integral, organizado como Escola-classe e Escola-Parque, inaugurado em 1950.

Entre os anos de 1951 e 1952, respectiva, e simultaneamente, assumiu a Secretaria Geral da Campanha de Aperfeiçoamento de Pessoal de Nível Superior, transformada por ele num Órgão - Comissão de Aperfeiçoamento de Pessoal de Nível Superior (CAPES) - e a direção do Instituto Nacional de Estudos Pedagógicos (INEP), onde criou o Centro Brasileiro de Pesquisas Educacionais (CBPE).

Enfim, na década de 50, manteve intenso debate a respeito de questões da educação pública, por meio de conferências, manifestos, e a publicação de dois livros: A educação $e$ a crise brasileira (1956) e Educação não é privilégio (1957). O último publicado em meio às polêmicas em torno da Lei de Diretrizes e Bases da Educação Nacional causou aos educadores católicos e instituições particulares desagravos, de modo que em 1958 foi lançado o "Memorial dos Bispos" que pedia sua demissão do INEP. Além de ser mantido no cargo, ainda foi convidado a realizar junto a Darcy Ribeiro a Universidade de Brasília (UNB), sendo designado em 1961 para a vice-reitoria.

Em 1964, após a deposição de João Goulart da Presidência pelo golpe militar, Anísio Teixeira foi afastado da reitoria da UNB, retornando aos Estados Unidos na condição de professor visitante na Universidade da Columbia (1964) e na Universidade New York (1965), segundo Gondra e Mignot (2006) e de acordo com o Guia das Escolas de Anísio Teixeira (2006) também na Universidade de Califórnia (1966). O educador baiano, retornou ao Brasil em 1967, organizando coletâneas e reeditando trabalhos antigos, como: Pequena 
Introdução à filosofia da educação (1967), Educação é um direito, Educação no Brasil e Educação e o mundo moderno (1969). Em 1971 aceita ser candidato a uma vaga na Academia de Letras, porém, em suas atividades interrompidas por ocasião de sua morte ${ }^{11}$ em março daquele mesmo ano.

Anísio Teixeira, ao longo de sua trajetória profissional, não só ocupou distintos cargos na administração pública educacional, como também criou instituições. Sem dúvida, o registro do seu nome na história da educação brasileira deve-se em grande parte, à materialização de suas ideias advindas do pragmatismo filosófico de John Dewey. Junto a outros companheiros defensores da educação pública foi signatário do Manifesto dos Pioneiros da Educação Nova de 1932, e no decorrer da década de 1930 muitas das concepções propostas no documento, foram fruto de debates. Nota-se a influência desse período no texto de 1952, A reconstrução educacional brasileira, presente no livro Educação no Brasil (2011), pontuando aspectos que caracterizavam a crise educacional brasileira do período.

Muitas das fontes do autor encontram-se na Biblioteca Virtual Anísio Teixeira $(\text { IBICT })^{12}$, e também, no arquivo Anísio Teixeira, no acervo documental do Centro de Pesquisa e Documentação de História Contemporânea do Brasil (CPDOC), encontram-se manuscritos, impressos e artigos. Também no IBICT existe um bom acervo de produções científicas sobre o educador ${ }^{13}$.

Para alcançar a sua base teórico-filosófica é indispensável que, preliminarmente, se exponham aspectos fundamentais de sua visão de Educação frente à sociedade burguesa e que fecundaram suas propostas em direção a um movimento para uma escola nova para todos, laica, gratuita, obrigatória, expressa no Manifesto dos Pioneiros da Educação Nova (1932).

\title{
1.1 Anísio Teixeira e o projeto liberal-democrático: Educação - o instrumento à liberdade e à igualdade.
}

\begin{abstract}
A igualdade de oportunidades manifesta-se pelo direito a educação e pela continuidade do sistema de educação, organizado de forma a que todos, em igualdade de condições, possam dele participar e nele continuar até os níveis mais altos (TEIXEIRA, 2009, p. 61).
\end{abstract}

Para Anísio Teixeira (2009), oferecer a educação é o dever supremo da democracia e o Estado tem a função suprema de propiciá-la a todos e a cada um. O princípio fundamental da forma social democrática, consiste em dar a cada indivíduo a sua igualdade política, isto é, oferecer-lhes, oportunidades iguais de desenvolvimento humano à sua participação social. A educação seria o instrumento suficientemente amplo e apaziguador à justiça social dos homens. Para ele, os seres humanos são diferentes, nascem biologicamente desiguais, mas a educação aplainaria as desigualdades naturais e criaria o saudável ambiente de competição entre ricos e pobres com as mesmas possibilidades de destino e de êxito, assim, "a educação é, portanto, não somente a base da democracia, mas a própria justiça social" (TEIXEIRA, 2009, p. 108).

Em um balanço no livro Educação no Brasil, Anísio Teixeira assinala que o nosso país começou a fazer a sua revolução industrial ou tecnológica, e com um rol de consequências na vida prática, na divisão do trabalho, na produção em massa, no enriquecimento nacional e na sua crescente urbanização, exige a criação de um sistema comum e sólido de educação popular, pois as próprias contingências de crescimento reclamam medidas e instituições como as das leis do trabalho urbano e rural, assentadas em 
um robusto e consistente sistema de educação pública. Tratava-se de "realizar, simultaneamente, as 'reformas de base', inclusive a reforma agrária, e o sistema universal de educação que não chegamos a construir até hoje, já no meado do século XX" (TEIXEIRA, 2009, p. 30).

Havia uma grave crise na educação brasileira em relação a isso, como também um relativo consenso, afirmava Anísio Teixeira, a questão, porém, era analisar as causas e indicar os caminhos mais recomendáveis e com novas perspectivas convergentes a diretrizes comuns, oferecendo aos indivíduos a educação formal e escolar.

Anísio Teixeira examinou a educação da nossa civilização e o panorama do ensino brasileiro. Afirmava que, em rigor, até o século XVIII, a nossa civilização não teve outra escola, senão aquela destinada à formação de intelectuais, de letrados, de eruditos, de homens do saber ou de arte porque a escola, propriamente dita, surgiu como instituição especializada para manter e desenvolver a cultura intelectual e artística da humanidade, privilegiando um pequeno grupo de especialistas do saber e das profissões de base técnica e científica.

Anísio Teixeira reclamava uma educação mais genérica e técnico-científica, - uma vez que a ciência viera revolucionar os métodos de trabalho e de vida humana. De tal maneira, essa educação permitiria a todos integrar-se aos novos níveis que a sociedade atingiria. A escola formava uns poucos, cuja tradição era cultivar as letras, a ciência ou as artes. Assim ele destaca:

Tal escola não visava formar o cidadão, não visava formar o caráter, não visava formar o trabalhador, mas formar o intelectual, o profissional das grandes profissões sacerdotais e liberais, o magistério superior, e manter, enfim, a cultura intelectual, especializada, da comunidade, de certo modo distinta da cultura geral do povo e, sobretudo, distinta e independente de sua cultura econômica e de produção (TEIXEIRA, 2009, p. 44).

Sintetiza nessa passagem a sua percepção e sua crítica da educação altamente especializada, "livresca", e "erudita" reclamando uma educação escolar que atenda a todos, nas suas palavras, uma escola para o homem comum e, não apenas, para um reduzido grupo de intelectuais, letrados, cientistas e artistas. Anísio Teixeira (1971) aspirava a uma escola universal proclamada na Convenção Revolucionária Francesa. Tornava-se indispensável examiná-la e caracterizar com precisão alguns conceitos e ideais a fim de evitar quaisquer confusões impeditivas à solução aceitável a um novo estágio da humanidade. Fundamentaria nesse pensamento o ideal de uma educação escolar para todos, e a escola viria a ser - "não a especialização de alguns indivíduos - mas a formação comum do homem e à sua posterior especialização para os diferentes quadros de ocupações, em uma sociedade moderna e democrática" (TEIXEIRA, 1971, p. 12).

Com consciência histórica, entendia as transformações na base material, articuladas à ciência, responsável pela edificação da sociedade moderna, exigindo a reconstrução da concepção do mundo e, por conseguinte, novas responsabilidades morais e sociais necessárias à consolidação de novos princípios. Todavia, a atitude do homem moderno não deveria repousar nas conclusões da ciência, como um saber pronto e acabado, mas "no método científico que lhe está dando um novo senso de segurança e responsabilidade" (TEIXEIRA, 1934, p. 31).

Para Anísio Teixeira o que distingue o homem moderno dos homens de outros tempos é a conquista objetiva do progresso, pois aqueles que nos precederam sofreram mais do que nós porque não tinham a facilitação proporcionados pelo progresso científico. A 
ciência tornou possível um bem sem precedentes para a humanidade, exigindo uma nova atitude espiritual para a construção de um novo homem: um ser independente e responsável é o que a nova escola deve vir a preparar.

Anísio, um liberal otimista, desconsiderou que o progresso científico carrega uma contradição, pois a despeito dos seus avanços como já mencionado, existem também os problemas gerados pelo uso capitalista da ciência, a exemplo da questão ecológica que atualmente coloca em risco a própria existência humana. Ademais, os seus benefícios não foram estendidos à grande maioria da população. Nessa universalidade de Anísio Teixeira, a nova ordem de mudanças constantes, impõe-se aos campos singulares, entre eles, o da educação escolar e a revisão dos conceitos à formação do homem comum.

Esse educador reconhece a sociedade de classes, e nela, o privilégio "dos bem nascidos" situação contra a qual se opôs defendendo uma escola pública e única para todos ${ }^{14}$. Logo, Anísio Teixeira, entendia que na instrução pública, universal, laica, gratuita, obrigatória tal como aparece no "Manifesto dos Pioneiros da Educação Nova" ${ }^{15}$ ", definiria os aspectos centrais à orientação das políticas gerais na perspectiva de uma escola nova, na qual a escola primária seria o instrumento que promoveria a essência da democracia, quebrando a rígida estratificação social, estabelecendo a igualdade de oportunidades, e como consequência, reduzira também os graves desníveis econômicos da sociedade brasileira. Essa escola teria de "ser ativa, prática, de experiência e de trabalho", para a formação do novo homem comum, divergindo da escola segregadora e de preparos de intelectuais especializados, com a utilização de métodos e princípios próprios da educação medieval. Buscaria assim transformar a escola:

[...] na agência de educação dos trabalhadores comuns, dos trabalhadores qualificados, dos trabalhadores especializados em técnica de toda ordem e dos trabalhadores da ciência nos seus aspectos de pesquisa, ensino e tecnologia" (TEIXEIRA, 1971, p. 17).

Vê-se, por essa passagem, que em tal educação, a escola primária dotaria o estudante dos fundamentos básicos, sendo o essencial habilitar os alunos para os trabalhos comuns, sem a preocupação de preparo para os estudos posteriores. Havia em Anísio Teixeira o argumento típico do liberalismo clássico de que fora concedida a cada um a "equidade" fornecida pela educação primária. Nesse modelo ideal, seria permitido, a cada indivíduo com suas capacidades e suas singularidades o desfrute das oportunidades que a "escola" concederia, permitindo ainda, aos alunos extrapolar para níveis mais avançados, segundo seus dotes naturais. A universalização da escola pública oportunizaria os conhecimentos de base, possibilitando aos menos favorecidos economicamente "competir" em "justeza" e superar os condicionamentos materiais.

Não seria um despropósito frisar a incoerência dessa proposta educacional nos termos colocados por Anísio, pois os limites impostos aos pobres são inerentes às condições materiais no capitalismo, de modo que, as condições igualitárias para ricos e pobres, não se faz tão-somente via educação. Em especial uma educação de caráter prático embasada no pressuposto de que os dotados de "talentos" alcançariam os horizontes mais auspiciosos independentes de suas condições sociais de classe. Contudo, reconhece-se que, apesar de a educação ser um instrumento de ampliação de horizontes, ela não é condição determinante em face das múltiplas variáveis a que estão condicionadas as pessoas menos favorecidas no sistema capitalista.

É importante ressaltar que o educador, ao examinar a educação no Brasil tomando por referência o "arcaísmo da escola brasileira" ", critica a concepção de uma escola 
tradicional que destaca a cultura geral ou humanista, desvinculada das necessidades advindas da era industrial nascente, assim:

Ensinam-se, por êsse método expositivo, informações teóricas SÔBRE as línguas (latim, português, francês, inglês, espanhol), SÔBRE a geografia e a história, SÔBRE as ciências, e até SÔBRE a música e o trabalho manual. Como a escola é de "cultura geral", nada tem de caráter prático (TEIXEIRA, 1971, p. 19).

Portanto, os velhos métodos de ensino pela exposição oral, no qual os alunos anotam o que ouvem para mostrar o que sabem por meio de provas escritas e orais, são criticadas pelo pragmatismo de Anísio Teixeira que refuta o ensino o ornamental e livresco.

Em Educação Progressiva: uma introdução a filosofia da educação, Anísio Teixeira, ressalta os aspectos que viriam alterar profundamente o conceito da velha escola tradicional: “a) Precisamos preparar o homem para indagar e resolver por si os seus problemas; b) Temos que construir a nossa escola, não como preparação para um futuro conhecido, mas para um futuro rigorosamente imprevisível" (TEIXEIRA, 1934, pp. 29-30). Visando transformar a velha escola, buscava construir uma nova tradição: uma nova escola, pois, à formação do homem moderno, não seriam recomendáveis os métodos e os currículos da organização da escola tradicional.

A partir das críticas à escola tradicional, Anísio Teixeira propunha o fim da escola de tempo parcial, voltada exclusivamente para a formação intelectual e sugerindo um outro tipo de organização escolar: a escola de tempo integral visando formar alunos, também, nos seus aspectos éticos, estéticos e físicos.

\section{A gênese da Escola-parque}

Tal como anunciado na introdução, este trabalho propõe-se a discutir a organização do trabalho didático da Escola-parque do Centro Carneiro Ribeiro. Sem dúvida, desde o início de sua vida profissional, Anísio Teixeira engajou-se na defesa da escola pública e o instrumento que realizaria a educação escolar, seria por excelência, a escola pública primária.

O termo público refere-se ao acesso à educação escolar a despeito da condição de classe, em outras palavras, traduziria a democratização da educação brasileira. E nesse sentido, totalmente avesso à escola "tradicional", Anísio Teixeira faz um exame da educação escolar e reivindica a necessidade de novas técnicas e novos processos à plena realização dos ideais escolares à democracia.

Carecia então, para responder às necessidades da sociedade moderna, oferecer um novo modelo de escola primária, já não caberia ser apenas de instrução, como ocorria até então, pois a escola deveria oferecer à criança oportunidade completa de vida compreendendo atividade de estudos, de trabalho, de vida social, de recreação e de jogos, afirma Teixeira (1971). "Para esta escola, precisava-se, assim, de um novo currículo, um novo programa e um novo professor" (TEIXEIRA 1971, p. 129, grifo nosso). Eis que a essência da democracia para Anísio Teixeira, seria oferecer uma escola para todas as crianças em idade escolar, e com uma organização didática que permitisse aos alunos um estudo em tempo integral.

Como já assinalado anteriormente, logo após assumir a gestão do Ensino na Bahia, Anísio Teixeira viajou para os Estados Unidos da América, e visita vários estabelecimentos ligados à Educação. Chamou-lhe a atenção de modo singular a organização escolar 
"platoon"17, em Detroit. Segundo Anísio Teixeira (2006), Detroit enfrentava problemas de toda ordem, resolvendo os impasses da educação com o aporte das mais adiantadas conquistas modernas, constituindo um sistema de ensino, como um dos mais progressistas e de mais requintada organização cientifica.

O sistema platoon, nas palavras do educador brasileiro, é um tipo de escola criada pela engenhosidade americana, em essência, uma escola elementar que funciona simultaneamente em dois grupos: um deles, com as matérias fundamentais do curso elementar, e o outro destinado às matérias especiais. Esse sistema, além de oferecer um grau superior de eficiência educativa, seria também, mais vantajoso do ponto de vista econômico, haja vista a aplicação mais eficiente ${ }^{18}$ do edifício e do trabalho do professor: "o plano procura realizar o ideal de um programa completo, com economia de salas, porque a escola funciona em dois grupos e com economia de tempo, porque cada professor trabalha um completo" (TEIXEIRA, 1971, p. 183).

Sua instalação, por ocasião de sua visita a Detroit, já contava 10 anos desde quando o sistema começara a ser estendido a outras escolas, e poderia ser chamado de evolução da escola primária, caracterizada pela transformação do seu programa, dos seus métodos de ensino e dos seus objetivos ou finalidades. Em suma, mudariam os objetivos, bem como os métodos e currículos:

A escola, em resumo, deixou de ser, a casa onde se estudavam alguns assuntos especiais, que, como se dizia, preparavam para a vida, para ser o 'lugar onde as crianças vivem e diariamente são postas em contato com a reais experiências industriais e sociais, da comunidade e da vida, experienciais que as educam e armam para os mais árduos problemas de existência adulta que as espera' (TEIXEIRA, 1971, p. 180).

Eis a escola que atenderia à moderna civilização dinâmica e mutável. Esse sistema ofereceria a escola elementar uma organização didática mais flexível, com edifícios que seriam construídos e adaptados aos fins da nova organização. A distribuição equilibrada e harmônica das matérias, bem como a ênfase aos aspectos sociais da educação, exigem edificações com espaços, instrumentos e aparelhamentos especiais para tal empreendimento.

Investir no ensino primário no Brasil tornara-se a grande razão de Anísio Teixeira, pois visava a um só tempo resolver o problema da infância abandonada e da escola primária. Um escola no Brasil com base no sistema platoon, viria atender à expectativa de integrar toda a população em idade escolar à sociedade moderna. Anísio Teixeira projetara, no bairro da Liberdade, um dos bairros mais pobres de Salvador (BA), os Centros de Educação Primária, também conhecidos por Centro de Educação Popular, sendo o Centro Carneiro Ribeiro, o modelo a ser implantado em outros Estados brasileiros.

Face ao objetivo que se propõe nesta investigação, cabe uma indagação: Em que a educação democrática defendida por Anísio Teixeira com a proposta de escola de tempo integral, se distingue da educação moderna inspirada na perspectiva liberal burguesa de Coménio? Foi preciso, então, adentrar essa escola e a partir da categoria Organização do Trabalho Didático formulada por Alves, apreender os aspectos que a compõe:

a) Ela é sempre uma relação educativa que coloca, frente a frente, uma forma histórica de educador e uma forma histórica de educando (s), de outro,

b) Realiza-se com a mediação de recursos didáticos, envolvendo os procedimentos técnico-pedagógicos do educador, as tecnologias 
educacionais pertinentes e os conteúdos programados para servir ao processo de transmissão do conhecimento,

c) E implica um espaço físico com características peculiares, onde ocorre (ALVES, 2005, pp. 10-11).

Esses três aspectos ofereceram elementos fundamentais para a realização da discussão acerca da proposta educacional de Anísio Teixeira. Nesse texto, o foco na Escolaparque considera que a organização do espaço físico determinaria a singularidade da proposta educacional de Anísio, pois essa distinguiria a relação educativa, os instrumentos de trabalho do professor e por conseguinte os conteúdos ensinados.

Ao considerar esses três aspectos constituintes do trabalho didático, apontam alguns pontos que caracterizam as condições materiais que foram basilares à universalização do ensino na escola moderna. Um deles é a divisão do trabalho didático. Organizado por níveis e seriação de estudos, tendo por fundamento o modelo da "manufatura ${ }^{19}$ que se desenvolveu como método de trabalho, na forma de um sistema cooperativo, conduzindo alteração substantiva no modo de produção capitalista", como assinala Fernandes (2014).

Conforme Alves (2001), Coménio inspirado naquele modelo concebe a escola semelhante a uma oficina de homens, onde cada um com o seu instrumento realiza as atividades que lhe são pertinentes. Na escola, o instrumento de base que compõe "o trabalho didático em seu conjunto é o livro, porém, um livro específico, com características bem peculiares, em sua forma e conteúdo, em duas versões, sendo um com orientações para o trabalho do mestre e o outro para atividade do aluno", segundo Fernandes (2014, p. 49) face ao que escreveu Coménio:

[...] aos educadores da juventude, é necessário dar normas, em conformidade com as quais executem as suas obras, isto é, devem escreverse para uso deles Livros-roteiros que os aconselhem quanto ao que hão-de fazer, em qualquer lugar e de que modo, para que não se caia em erro. Os livros didácticos serão, portanto, de dois gêneros: verdadeiros livros de textos para os alunos, e livros-roteiros (informatorii) para os professores, para que aprendam a servir-se bem deles (COMÉNIO, 1957, p. 460, grifos do autor).

O barateamento dos serviços escolares é condição necessária para a universalização do ensino nesse sentido, a queda dos custos envolveria uma mudança nos elementos que compõem a organização do trabalho didático. As condições objetivas para estender o ensino a todos implicaria a elaboração de um instrumento com menor custo e maior aproveitamento de tempo, daí os dois gêneros de livros didacticos. Tratava-se, segundo Alves (2001, p. 86) de objetivar e simplificar num único instrumento os conteúdos, pois nele se poderia "consubstanciar uma síntese de conhecimentos humanos sob uma forma mais adequada ao desenvolvimento e à assimilação da criança e do jovem".

Era necessário superar as limitações impostas pelo ensino preceptorado como atividade complexa, pois até a Idade Média, o mestre, por excelência, era um erudito, sendo os instrumentos de referência os clássicos, livros que exigiam por sua natureza um conhecimento muito além da média dos homens. O manual didático, na condição de instrumento de trabalho do professor, tornou-se, em grande medida, a resolução do problema que se impunha para viabilizar a expansão da escola: atender um grande número de alunos e responder a falta de professores. 
O tipo de educador e de relação educativa, que até então se realizara, não comportava o seu lema: Ensinar tudo a todos, sendo preciso dar ao trabalho didático uma forma simples e objetiva, cujo fundamento seria nas palavras de Coménio (1957) "ensinar e aprender rapidamente, facilmente, vantajosa e solidamente". A esse respeito comenta Fernandes (2014, p. 48):

\begin{abstract}
Ensinar tudo a todos não significava ensinar os conhecimentos que conduzissem à reflexão, [...] Dado o pragmatismo inerente ao pensamento burguês, convinha dar a todos os "fundamentos", de acordo com as necessidades devotadas ao fazer. Tratava-se de ensinar um conhecimento exato e profundo, mas que lhes fosse funcional, isto é, útil e que o preenchesse por toda a sua vida; [...] Nesses termos, a organização didática deveria ser constituída com um programa capaz de educação a todos os homens, os conteúdos básico: ler, escrever, contar, e medir, além de conteúdos de ordem mais geral, com métodos objetivos e práticos, metas bem definidas e um único instrumento conduzindo-os em conjunto.
\end{abstract}

Coménio recomendava a exclusividade do manual didático, prescrevendo nele, todo programa escolar, de tal maneira que, mesmo pessoas não tão hábeis para ensinar poderiam fazê-lo, uma vez que a elas caberia apenas reproduzir o conteúdo, a partir do instrumento já preparado:

\begin{abstract}
A cada classe sejam destinados livros de textos próprios, que contenham todo o programa prescrito para essa classe (quanto à instrução, à moral e à piedade), para que, durante o espaço de tempo em que os jovens são conduzidos pelo caminho destes estudos, não tenham necessidade de nenhum outro livro, e com a ajuda desses livros possam ser conduzidos infalivelmente às metas fixadas. [...]. Portanto em conformidade com o número de classes, estes livros serão seis, diferentes entre si, não tanto pelas matérias tratadas, como pela forma. Com efeito, todos tratarão de todas as coisas; mas o primeiro apresentará os aspectos mais gerais, mais conhecidos e mais difíceis [...]. (COMÉNIO, 1957, p. 430, grifo nosso).
\end{abstract}

Enfim, esse instrumento, se por um lado, permitiu a expansão escolar, por outro, suprimiu a totalidade como expressão do conhecimento, dada a simplificação e objetivação do trabalho, resultando a fragmentação dos conteúdos e, assim, "um progressivo aviltamento do conhecimento sistemático transmitido através do currículo" (ALVES, 2001, p. 169).

Após esta síntese acerca dos elementos que fundamentaram a universalização na escola moderna, pode-se observar que a organização do trabalho didático, pode ser a expressão do tipo de ensino que se observa na sociedade contemporânea. Na sequência discutiremos, como já assinalado, em que pontos a organização do trabalho didático na Escola-parque se diferencia da perspectiva comeniana.

\title{
3 A organização do trabalho didático na Escola-parque
}

Para Anísio Teixeira, as mudanças com a aceleração do desenvolvimento tecnológico e científico, reclamam, por si, oportunidades educativas diferentes àquelas que vinham sendo operacionalizada no século XIX, ou mesmo até a Segunda Guerra Mundial, já no século XX. 
Segundo o educador, o desenvolvimento coloca para todos, ricos e pobres, a necessidade de um nova escola para atender às exigências das transformações sociais, particularmente, as nações mais atrasadas.

Assim, estava colocada para o educador a exigência de uma nova escola. Para tanto, em sua concepção caberia, antes de qualquer ação, uma transformação de conceitos para a criação de uma escola comum para todos e, sobretudo, uma profunda alteração da natureza do conhecimento e do saber. Logo:

\begin{abstract}
A escola deveria deixar de ser uma instituição segredada e especializada de preparo de intelectuais para transformar-se na agencia dos trabalhadores comuns, dos trabalhadores qualificados, dos trabalhadores especializados em técnicas de toda ordem e dos trabalhadores da ciência nos seus aspectos de pesquisa, teoria e tecnologia. [...] Em todas essas modalidades, em face do caráter novo do conhecimento cientifico, o ensino se tem de fazer pelo trabalho e pela ação, e não somente pela palavra e pela exposição, como outrora [...] somente através da experiência vivida e real é que a mente aprende e absorve o conhecimento e o integra em formas novas de comportamento (TEIXEIRA, 1971, p. 17, grifo nosso).
\end{abstract}

Ao contrário da escola intelectualista, a nova escola deveria dar lugar, em sua forma e estrutura a uma nova organização para atender as diversas vocações, ofícios e profissões: uma escola moderna, prática e eficiente. Tratava-se de produzir uma escola para atender às exigências "em que a nascente sociedade liberal e progressiva começou a desdobrar-se" (TEIXEIRA, 1971, p. 12). Reforça-se nesta passagem, que essa escola não prepararia os alunos para estudos ulteriores, mas massificaria o ensino para o trabalhador brasileiro. A educação escolar pública universal deveria constituir-se com um novo espaço para "dar a cada indivíduo a oportunidade de ser na sociedade, aquilo que seus dotes inatos, devidamente desenvolvidos, determinassem" (TEIXEIRA, 1971, p. 12).

Ilustra-se este pensamento com uma passagem do Manifesto dos Pioneiros da Educação Nova de 1932:

Desprendendo-se dos interesses de classes [...] a educação perde o "sentido aristológico", para usar a expressão de Ernesto Nelson, deixa de constituir um privilégio determinado pela condição econômica e social do indivíduo, para assumir um "caráter biológico", com que ela se organiza para a coletividade em geral, reconhecendo a todo indivíduo o direito de ser educado até onde permitam as suas aptidões naturais [...]. A educação nova, alargando a sua finalidade para além dos limites das classes, assume 
uma feição mais humana, a sua verdadeira função social, preparando-se para formar a "hierarquia democrática" pela "hierarquia das capacidades", recrutadas em todos os grupos sociais, a que se abrem as mesmas oportunidades de educação. [...] com o fim de dirigir o desenvolvimento natural e integral do ser humano em cada uma das etapas de crescimento", de acordo com uma certa concepção de mundo. [...] a educação nova que, certamente pragmática, se propõe ao fim de servir não aos interesses de classes, mas aos interesses do indivíduo, e que se funda no princípio da vinculação da escola com o meio social, tem o seu ideal condicionado pela vida social atual, mas profundamente humano de solidariedade, de serviço social e cooperação (O MANIFESTO..., 2006, p. 4).

Eis o caráter humanista da nova escola. Numa clássica perspectiva liberal e idealista oferecer a todos os indivíduos o desenvolvimento de suas aptidões naturais seria suficiente à superação imposta pelos limites das classes sociais. Para servir aos interesses do indivíduo é bastante fundar-se no princípio da integração da educação a sociedade. Tratava-se de uma escola que oferecesse um método de vivenciar situações de vida real para despertar em cada ser, o juízo para enfrentar os problemas que encontrará. De tal sorte, cada indivíduo afeito ao sentido de responsabilidade social e com a consciência do que se passa o seu redor - livre, informado - estaria em condições de igualdade ser capaz de a um só tempo servir a sociedade e resolver seus próprios problemas.

Para Teixeira a escola primária ofereceria, potencialmente, igualdade de oportunidades: a escola de tempo integral, uma escola prática, de formação de hábitos para o trabalho, para participar na sociedade. Para uma civilização que começa a industrializarse, aspira-se uma escola primária obrigatória, forte e sólida, "de currículo completo e dia letivo integral destinado a preparar o cidadão nacional e o trabalhador ainda não qualificado e, além disto, estabelecer a base igualitária de oportunidades [...]” (TEIXEIRA, 1971, p. 78).

Em assim sendo, a educação comum para todos, jamais deveria limitar-se à alfabetização das três técnicas básicas: ler, escrever e contar. Embora, em nível elementar, tanto quanto possível, os alunos teriam de adquirir hábitos de competências e de ação eficientes para o trabalho. Sendo a escola primária, por excelência, a formadora de hábitos morais, estéticos, éticos e de cuidados primários de saúde, imperiosamente, para as suas atividades devem ser dedicadas um dia completo. Eis, que a escola primária não deve esgotar-se numa escola de alfabetização, simplificada em seu objetivo escolar, isto é, reduzida apenas a instrução tradicional em tempo parcial.

Para a construção dessa escola, a solução do problema projeta-se um ensaio no Centro Carneiro Ribeiro, construído com espaços para as atividades práticas e sociais, em que o aluno pelo senso de responsabilidade e trabalho material, executará coisas de valor utilitário, usufruindo ao mesmo tempo do lazer, explica Hermes Lima (1978). Conforme o mesmo autor, a escola edificada por Anísio Teixeira na Bahia, era animada pela vocação, que para além de reproduzir o ambiente existencial da sociedade, ofereceria o estudo, trabalho, lazer e convívio.

Neste estudo, para o entendimento dessa nova escola cumpre apresentar a organização do trabalho didático que a comportaria, especialmente, na escola-parque. Funcionando em tempo integral, em regime de semi-internato ${ }^{20}$, o dia escolar divide-se em dois períodos: um de instrução nas escolas-classes, para as matérias curriculares comuns de instrução intelectual e no outro, a de educação nas escolas-parque, para as tarefas propriamente sociais, do trabalho, da educação física, além de outras, em que predomina o sentido de atividade completa. Em oposição a tendência à simplificação destrutiva e à improvisação educacional que liquidou a escola primária, designou ao Centro Carneiro 
Ribeiro função mais ampla a cumprir, onde teriam as crianças na Escola-parque, a complementação "via educação", integralizando o tempo de estudo.

Em seu discurso de inauguração do referido Centro, o educador tece suas críticas a escola brasileira:

[...] em um círculo vicioso se meteu a nação. Improvisam escolas de todo jeito porque não acreditam em escolas senão como formalidade social, [...] porque só tem escolas improvisadas e inadequadas não acreditam em escolas que possam ser formadoras eficiente de uma ordem social. Em volta de si vê escolas improvisadas ou desorganizadas, sem vigor nem seriedade [...] (TEIXEIRA, 1971, p. 143).

Essa escola não tinha crédito diante do povo brasileiro, afirmava Anísio, pois até aquele momento, efetivamente, não educara. Nesse sentido, sem desprezar as questões de economia, à recuperação da escola pública primária, construiu-se o Centro Carneiro Ribeiro, com três pavilhões, de três grupos escolares:

[...] cada conjunto para 4.000 alunos, compreendendo 4 escolas-classe, para 1.000 alunos cada uma, em 2 dois turnos com 500 - ou seja, com doze salas de aula, no mínimo - e uma escola-parque, com pavilhão de trabalho, ginásio, pavilhão de atividades sociais, teatros e biblioteca para os referidos 4.000 alunos, em turnos de 200 pela manhã e 200 à tarde, e ainda edifícios de restaurante e de administração (TEIXERIA, 1971, p. 130).

Eis o plano para renovar a escola na cidade de Salvador, restaurando-a em sua estrutura, com o funcionamento em tempo integral, marcando a sua distinção com um programa tão rico quanto possível, sendo que:

A escola primária seria dividida em dois setores, o da instrução, propriamente dita, ou seja, o da antiga escola de letras, e o da educação, propriamente dita, ou seja, o trabalho da escola ativa. No setor instrução, manter-se-ia o trabalho convencional da classe, o ensino de leitura, escrita e aritmética e mais ciências físicas e sociais, e no setor educação as atividades socializantes, a educação artística, o trabalho manual e as artes industriais e a educação física (TEIXEIRA, 1971, p. 145).

Note-se, o autor distingue instrução e educação, daí a organização do espaço físico denominado escolas-classe e escolas-parque. A primeira destinada à educação intelectual sistemática, e a segunda com um conjunto de edifícios centrais para as demais atividades no centro tendo como orientação a experiência da vida real.

Percebe-se, em suas exposições, a ênfase dada pelo educador às atividades educativas que expressariam a escola ativa, pois além de socializante, e de trabalho, concorreria "imediatamente para o preparo do produtor, quando ministrada com eficiência". É notório o posicionamento de Teixeira, acerca da valorização da educação como ferramenta objetiva na escola primária assim, é a escola-parque, o elemento que distingue a organização do trabalho didático, na qual se educa a criança desde os primeiros anos de escolarização a participar da consolidação e da expansão da riqueza que adviria da escola ativa.

O educador adotou o pensamento de Dewey, a sua filosofia, a sua democracia, bem como, uma nova psicologia da aprendizagem, elementos básicos para uma escola nova ou uma escola progressiva. O termo "escola nova", para Anísio, não era adequado para qualificar a renovação, mas de início marcaria as fronteiras dos campos adversos. 
Preferencialmente, "escola progressiva", como já era chamada nos Estados Unidos, a distinguiria. Com esta terminologia, seguramente, ela expressaria uma escola de constante mudança pois, com o viés científico criaria "uma situação real de vida e de experiência" (TEIXEIRA, 1950, p. 43).

Embasado filosoficamente pela perspectiva de uma escola ativa e progressiva, marca-se na preocupação do educador a diversificação do trabalho didático, conferindo à escola primária os seguintes aspectos: "preparação" e "execução". O primeiro ligado aos estudos no domínio intelectual, realizado na escola-classe ${ }^{21}$ que corresponderia a uma sala de aula comum da escola tradicional. Com isso, supostamente, Anísio manteria a mesma organização do trabalho didático, o que se considera uma incoerência, já que ele estabelece fortes críticas à velha escola.

O segundo refere-se, substancialmente, à "execução" integrando, nas experiências de ação responsável da escola-parque, um conjunto de atividades com oficinas de trabalho sociais: lojas, clubes, de artes de educação física, organizações infantis, música, teatro, dança. Tratava-se do aprendizado em ação para fins de resultados práticos e exteriores pois, uma vez que se estimulava a iniciativa para o pleno e rico exercício de vida nas atividades diversificadas, espaço onde se educariam, fundamentalmente, para o ajustamento social: "A 'grande sociedade' está a se constituir e o homem deve ser preparado para ser um membro responsável e inteligente dêsse novo organismo" (TEIXEIRA, 1950, p. 23).

As críticas que Anísio Teixeira faz aos métodos e conteúdos reduzidos a mera alfabetização da velha escola são insuficiente, pois sua proposta não ultrapassa os limites daquela alfabetização simplificada por ele próprio criticada. Mesmo a escola de tempo integral por ele proposta não possibilita aos estudantes um conhecimento que lhes permita questionar a sociedade de classe burguesa, pois acaba por adaptá-los à nova ordem social já estabelecida. Segundo Anísio o sentido de integração refere-se à adaptação de cada indivíduo da comunidade escolar, para tornar-se amanhã o "ser" da sociedade: o operário, o estudioso, o artista, o esportista, o cidadão útil, responsável e feliz. Eis a concepção de cidadania reivindicada pelo nascente liberalismo burguês da sociedade capitalista, no Brasil. A cada um, a escola primária ofereceria as condições de realização, cuja competência se traduz na singularidade de cada ser. Daí o corolário imperativo: "Tal escola não é um suplemento à vida que já leva a criança, mas a experiência da vida que vai levar a criança em uma sociedade em acelerado processo de mudança" (TEIXEIRA, 1971, p. 131).

Pode-se dizer que a organização do trabalho didático instaurado nas escolas-parque é uma iniciativa, que, se por um lado, concorre para a solução do problema da escola primária comum no Brasil, por outro, é orientada pelo idealismo, com vistas a atender as diretrizes da nova sociedade burguesa ao invés das necessidades educacionais que propiciariam as crianças uma formação integral conferindo-lhes os conhecimentos para além de sua adaptação.

Anísio Teixeira reconhecia que o capitalismo gera desigualdades, entretanto, em seu ideário liberal e em seu idealismo - a margem da realidade objetiva - explica a superação da sociedade de classe, a luz do "espírito", daí o corolário da força da escola, sobretudo, a escola primária na equalização das desigualdades sociais: "ela é o fundamento, a base de toda nação. Dela depende o destino ulterior de toda cultura de um povo moderno" (TEIXEIRA, 1971, p. 77). Assim, de acordo com Anísio Teixeira, a rígida estratificação social e os problemas econômicos seriam solucionados.

Percebe-se, um Anísio, otimista e idealisticamente esperançoso na escola primária em tempo integral como a fonte da consciência social e da equidade da sociedade capitalista. Ilustra-se assim, a presença do pensamento filosófico idealista em Anísio Teixeira com base em uma passagem de Marx e Engels em a Ideologia Alemã, na qual mostram o equívoco dos 
neo-hegelianos que explicam a realidade social descolada da sua materialidade. Para os autores:

[...] os jovens hegelianos consideravam as representações, os pensamentos, os conceitos - em uma palavra, os produtos da consciência por eles tornada autônoma - como os verdadeiros grilhões dos homens [...], é evidente que os jovens hegelianos têm de lutar apenas contra essas ilusões da consciência. Uma vez que, segundo suas fantasias, as relações humanas, toda a sua atividade, seus grilhões e seus limites são produtos de sua consciência [...] (MARX E ENGELS, 1991, p. 25).

Estes filósofos desvirtuavam suas críticas porque não estabeleciam a relação entre a realidade concreta e sensível, prescindindo do real pelo imaginário. A esse respeito compartilhamos com Souza (2010, p. 07) ao explicar que:

[...] a autonomia do pensamento em relação aos determinantes materiais, que acredita-se, tem contribuído até os dias de hoje para que as questões humanas possam parecer fenômenos produzidos pela consciência, sem qualquer lastro com a realidade social.

Ressalte-se ainda, o educador brasileiro atribui quase, exclusivamente à escolaparque potencial formidável na formação da criança, mostra-se, porém, refratário a uma educação do tipo propedêutica e acadêmica. Apesar de este estudo encontrar-se ainda em andamento, infere-se que o educador a despeito de suas críticas à "velha escola", designando-a: "escola tradicional" - uma escola arcaica e obsoleta - mantém seu modelo nas escolas-classe. Tal inferência justifica-se por este extrato do livro Educação não é privilégio, citado anteriormente na página 19 deste texto "[...] No setor instrução, manterse-ia o trabalho convencional da classe, o ensino de leitura, escrita e aritmética [...] e sociais, e no setor educação as atividades socializantes $[\ldots]^{22}$.

Notem-se, as escolas propostas para o Centro Carneiro Ribeiro. Elas, não constituem de fato, escolas complementares e renovadas, mas duas escolas diferentes, em que as escolas-parque, se distinguem-se das escolas-classe pela proposta da atividade pela criança - a criança ativa - sendo as primeiras, a expressão da escola renovada. Elas não são uníssonas em sua proposta renovadora no que refere à organização do trabalho didático.

A frase o "trabalho convencional da classe" seguida da nomeação das disciplinas tradicionalmente escolares, indica apenas uma referência às matérias comuns da educação escolarizada no âmbito da escola-classe. Percebe-se, no "novo modelo escolar" uma dualidade quando o educador escreve: "A escola primária seria dividida em dois setores, o da instrução, propriamente dita, ou seja, o da antiga escola de letras, e o da educação, propriamente dita, ou seja, o trabalho da escola ativa,"23. Eis aí a escola primária gratuita $\mathrm{e}$ universal. A escola da educação, isto é, a escola-parque ofereceria vida plena e integral que prima pela formação de hábitos morais e sociais necessárias à conformação da sociedade burguesa capitalista. Entende-se que o educador baiano centraliza nas escolas-parque a sua proposta de "renovação" em detrimento das escolas-classe que parecem continuar com o antigo modelo de trabalho didático. Tal questão será mais bem investigada e desvelada na continuidade desta pesquisa quando serão discutidas as escolas-classe.

Todavia, considerando que a escola progressiva deva ser a réplica da sociedade capitalista renovada com o advento do industrialismo, além da filosofia ativa, que propõe trazer a vida para dentro da escola, à sua concretização carecia também de mudança no método de ensino. Surgiu, assim, uma nova psicologia para nesse novo método mediar uma 
relação educativa distinta daquela em que o aluno decorava a lição e o professor, estabelecendo uma organização didática rotineira prelecionava por meio do livro feito especificamente para este fim, composto por lições para as atividades escolares. Cabia aos programas apenas determinar o tempo de estudo de tais lições. O bom aluno era aquele que se adaptava a esse processo livresco.

Nessa nova perspectiva psicológica defende-se que "Aprender significa ganhar um modo de agir" (TEIXIERA, 1971, p. 35) para agir do modo aprendido. Para Teixeira (1971) reagimos a estímulos que recebemos por meio dos sentidos internos e externos, assim, frente a uma situação o nosso organismo fatalmente reage, sendo a aprendizagem sempre uma forma especial de reação. Logo, não se aprende, senão quando se pratica: "Aprender é um processo ativo de reação a certas coisas, selecionar reações apropriadas e fixá-las depois no organismo", afirma o educador (Ibid., p. 36). Certas interpretações gerais do ato de aprender são chamadas de "leis": as duas mais importantes são a de prática e efeito e a de inclinação ("realidiness"). Entretanto, segundo a lei do efeito só se aprende, aquilo que se pratica por gosto e satisfação, por isso, o interesse do aluno orienta o que ele vai aprender.

$\mathrm{Na}$ "escola progressiva as matérias são a própria vida distribuída por 'centros de interesse ou projeto"” (Ibid., p. 41). Esse método permite uma consideração acerca da relação educativa: a primazia do aluno na ação educativa com vistas à resolução do problema ou execução do projeto e, com efeito, impõe-se ao professor uma posição secundária, uma vez que ensinar é "guiar" o aluno numa situação de experiência real oferecendo-lhe os recursos necessários à economia de seu esforço.

Em síntese, "a nova psicologia de aprendizagem obriga a transformar a escola em um centro onde se vive e não em um centro onde se prepara para viver" (Ibid., p. 38). Eis aí na escola ativa, mais um indício da centralização de sua proposta na escola-parque. Ao referir-se a "função de integral educação" o educador evidencia em sua proposta a subordinação dos conteúdos didáticos a um ambiente social no qual a criança possa vivenciar plenamente o aprender pela experiência, de tal sorte que, a escola não pode reduzir-se simplesmente a uma classe de exercícios intelectuais especializados.

Teixeira nos limites de sua concepção democrática burguesa, conclui, fundamentalmente, os pressupostos comenianos embasados nos conhecimentos básicos, generalistas e primordialmente úteis, sem os aprofundamentos que propiciariam aos estudantes realizar uma crítica radical e de conjunto à sociedade capitalista. A proposta de Anísio Teixeira não se distingue da escola liberal comeniana, exceto pela estrutura que propõe a organização do trabalho didático de sua proposta educacional em espaços físicos diferentes, bem como, pelo fato de ser em tempo integral a realização das tarefas escolares desenvolvidas no Centro Carneiro Ribeiro.

Influenciado pelo pragmatismo filosófico de John Dewey, eivado pelo subjetivismo burguês, marca-se nos fundamentos teóricos abalizadores da escola de tempo integral e frisase a democracia liberal burguesa, e nela, os limites à formação de um indivíduo com autonomia para enfrentar as contradições da sociedade moderna.

Finalizando, investir no ensino primário no Brasil tornara-se a razão de Anísio Teixeira, marcado, porém, por um idealismo romântico, à margem da base material, entendendo que a consciência social pública da educação como problema primordial do Brasil permitiria a equidade na sociedade de classes por meio da implantação escola progressiva. Não obstante, Anísio Teixeira tinha clareza das transformações das instituições humanas e defendia que com o desenvolvimento da ciência a escola deveria também ser "transformada". Teixeira (1950, p. 16) reconhece que o homem produz as obras humanas pois, em suas invenções, "Faz o nosso tempo tão diferente dos nossos antepassados". Corrobora uma perspectiva histórica de que a escola deve ser transformada, porém para 
cumprir tal desiderato devem ultrapassar o ensino organizado na escola moderna e o horizonte de que a sociedade burguesa é a única possível. Enfim, Anísio Teixeira considerava ainda que o progresso científico potencialmente traria a melhoria de condições de vida para toda a humanidade. O tempo encarregou-se de negar o seu otimismo.

Reiteramos, por fim, a centralidade da categoria organização do trabalho didático para análise da Escola-parque do Centro Carneiro Ribeiro. Trata-se, como explica Alves (2005) de uma categoria produzida no campo da educação a partir do referencial teórico metodológico marxista portanto, subordinada àquelas construídas no núcleo central da economia política. Nesse sentido, buscou-se assegurar o primado metodológico da totalidade à temática em questão e, investigar, na Escola-parque os fundamentos do trabalho didático, no qual evidenciou-se as características liberais burguesas que se revelam na proposta dessa escola. Desse modo, estabeleceram-se a partir dessa categoria as aproximações da proposta educacional da Escola-parque, com o trabalho didático instituído na didática comeniana.

\section{Referências}

ALVES, G. L. O trabalho didático na escola moderna: formas históricas. Campinas, SP: Autores Associados, 2005.

COMÉNIO. J. A. Didática Magna: tratado da arte universal de ensinar tudo a todos. $3^{\text {a }}$ ed. Fundação Caloustre Gulbenkian, 1957.

CARVALHO, V. B. As Influências do Pensamento de Dewey no Cenário Educacional Brasileiro. Revista Redescrições - Revista On Line do GT de Pragmatismo Ano 3, Número 1, 201. (Nova Série).

FERNANDES, E. Métodos e conteúdo de alfabetização em manuais didáticos no século $X I X$ e XX: de Calkins a Lourenço Filho. Tese (Doutorado). Universidade Federal de Mato Grosso do Sul, Campo Grande, 2014.

GUIA DAS ESCOLAS. Centro de Referência da Educação Pública da cidade do Rio de Janeiro. Prefeitura da cidade do Rio de Janeiro. 2006.

LIMA, H. Anísio Teixeira: estadista da educação. Ed. Civilização Brasileira, 1978.

MARX. K. E ENGELS, F. A Ideologia Alemã (Feuerbach). $8^{a}$ edição, Editora HUCITEC: São Paulo, 1991.

MARX, K. O capital: crítica da economia política. Livro Primeiro. O Processo de Produção do Capital, 12a edição, Volume I, Bertrand Editora Brasil S. A. 1988.

MIGNOT, A. V. GONDRA, J. G. A descoberta da América. In: NUNES, Clarice (Org.). Aspectos americanos de educação \& anotações de viagem aos Estados Unidos em 1927. Rio de Janeiro: Ed. UFRJ, 2006. p. 9-24.

O MANIFESTO dos Pioneiros da Educação Nova (1932). In: Revista HISTEDBR on line. Campinas, N. Especial, Agosto, 2006. <Disponível em 
<http://www.histedbr.fe.unicamp.br/revista/edicoes/22e/doc1_22e.pdf >. Acesso em 27/02/2017.

RATKE, W. Escritos sobre A Nova Arte de Ensinar de Wolfgang Ratke (1571-1635): textos escolhidos. Apresentação tradução e notas de Sandino Hoff. Campinas, SP: Autores Associados, 2008. (Coleção clássicos da Educação).

SANTOS, W. da S. O Liberalismo em Anísio Teixeira: os fundamentos para uma educação pública. Tese (Doutorado), Universidade Estadual de Campinas, Faculdade Educação, Campinas, SP, 2006.

SOUZA. A. A. A. de. A Pesquisa Educacional no Interior dos Programas de Iniciação Científica. In: Neres, C. C.; Costa, L. S. da (Orgs) Pesquisa em Educação, Políticas Públicas e Formação de Professores em questão. Campo Grande, MS: Life, Editora, 2016.

TEIXEIRA, A. S. Educação Progressiva: Uma introdução à filosofia da educação. Série III, Atualidade pedagógicas, V. 3 Biblioteca Pedagógica Brasileira. Campanha Editora Nacional São Paulo, 1958.

TEIXEIRA, A. S. Educação no Brasil, 4. Ed. Rio de Janeiro: Editora UFRJ, 2011.

TEIXEIRA, A. S. Educação e o mundo moderno. Rio de Janeiro: Editora UFRJ, 2006.

TEIXEIRA, A. S. Educação é um direito. 4. Ed. Rio de Janeiro: Editora UFRJ, 2009.

TEIXEIRA, A. S. Aspectos americanos da educação: anotações de viagem aos Estados Unidos em 1927. Rio de Janeiro: Editora UFRJ, 2006.

TEIXEIRA, A. S. Educação não é privilégio. $3^{\text {a }}$ ed. São Paulo, Editora Nacional, 1971.

TEIXEIRA, A. S. Em marcha para a democracia: à margem dos Estados Unidos. Rio de Janeiro: Editora UFRJ, 2009.

TEIXEIRA, A. S. Porque "Escola Nova". Boletim da Associação Bahiana de Educação. Salvador, n. 1930, pp. 2-30. 


\section{Notas}

${ }^{1}$ Professora da Universidade Estadual de Mato Grosso do Sul, Unidade Universitária de Campo Grande, Doutora em Educação (Universidade Estadual de Mato Grosso do Sul - UEMS - enil.fer@uol.com.br).

${ }^{2}$ Professor da Universidade Estadual de Mato Grosso do Sul, Unidade Universitária de Campo Grande, Mestre em Educação. (Universidade Estadual de Mato Grosso do Sul - UEMS - pauloedyr@uol.com.br).

${ }^{3}$ Designado com o nome: Centro Educacional Carneiro Ribeiro.

${ }^{4}$ O professor Sandino Hoff (2008) ao traduzir e apresentar a obra, Escritos sobre A Nova Arte de Ensinar de Wolfgang Ratke (1571-1635): textos escolhidos, esclarece que 45 anos antes da edição da Didática Magna de Comênio; o pedagogo alemão, Ratke (nascido em Holstein) já havia sinalizado a origem da escola burguesa com práticas escolares inovadoras à base da divisão do trabalho didático, com a utilização de manuais didáticos para uma nova arte de ensinar. Destaca-se a contribuição de Ratke na defesa da difusão da língua alemã, quando a burguesia representativa da força histórica em combate ao feudalismo, coloca em questão o Latim, no dominio da comunicação. Em 1612, frente as lutas travadas no campo da Educação entre as forças feudais e burguesas na constituição do capitalismo, o pedagogo alemão começa a elaborar os manuais didáticos para o ensino da língua nacional a prtir de 1614.

${ }^{5}$ C.f. VII Exposição de Obras Raras: Anísio Teixeira Centenário de Nascimento (1900-2000); Anísio Teixeira em movimento: A vida e as lutas de Anísio Teixeira pela Escola Pública e pela Cultura no Brasil (2002); por João Augusto de Lima Rocha (Org.) Anísio Teixeira e a educação: um roteiro possível de leitura (19391950), de Olinda Evangelista; Anísio Teixeira e a educação: um roteiro possível de leitura (1939-1950), de Olinda Evangelista, A Tradição desafortunada: Anísio Teixeira Velhos Testos e ideias atuais, de Hugo Lovisolo (1989);) e outros que podem ser acessados no Centro de Pesquisa e Documentação histórica (CPDOC). Além de livros - Clarice Nunes, Poesia da Ação (2000), Anísio Teixeira: a obra de uma vida (2001) de Carlos Monarcha (Org.); Estadista da Educação (1978) de Hermes Lima. Outra base de dados com um acervo formado por Produção intelectual, do educador Folhetos, Correspondências, Monografias, anotações de viagem Biblioteca do Instituto Brasileiro de Informação em Ciência e Tecnologia (IBICT).

${ }^{6} \mathrm{O}$ artigo foi publicado na Revista do Ensino, V.1 N. 3. 1924 e encontra-se na Biblioteca Virtual de Anísio Teixeira http://www.bvanisioteixeira.ufba.br/visita.htm

${ }^{7}$ Nas citações foram mantidas a ortografia original de Anísio Teixeira.

${ }^{8}$ A entrevista foi intitulada "Paris é um filho espiritual de Roma", realizada em 30/11/1925, http://www.bvanisioteixeira.ufba.br/visita.htm

${ }^{9}$ Parte deste relatório encontra-se também na Biblioteca Virtual Anísio Teixeira, mas na Fundação Getúlio Vargas/CPDOC, sob o código ATpi 24/25.00.00 (Filme 03) encontra-se completo.

${ }^{10}$ Grifo Nosso.

${ }^{11}$ É importante registrar que apesar de ter sua morte ter sido oficialmente acidental, quarenta e cinco anos (45) anos depois, novas análises negam esta primeira versão. Em reportagem editada por Beto Coura, no EBC Agência Brasil do dia 11 de março de 2016, o escritor e professor da Escola Politécnica da Universidade Federal da Bahia João Augusto de Lima Rocha contesta a versão oficial de que Anísio Teixeira caiu de um fosso do elevador do predio onde morava Aurélio Buarque de Holanda. O professor Lima Rocha tendo acesso ao laudo do Instituto Médido Legal e as fotos do educador bahiano analisou documentos, imagens e baseando-se também em depoimentos de pessoas próximas ao educador, afirma que a versão da queda é falsa. O laudo médico pericial do legista João Guilherme Figueiredo feito em 1971, permite negar a versão sustentada pelo governo da época. As análises mostram que a posição do corpo, os ferimentos na cabeça e a disposição dos objetos pessoais de Anísio Teixeira não correspondem ao que seria uma queda. "Hoje, comprova-se, documentalmente e fotograficamente, com laudos periciais, que não é verdade que Anísio Teixeira tenha caído no poço daquele elevador". Nesta edição o coordenador da Comissão Estadual da Verdade, na Bahia, Joviniano Neto, informa que pedirá à Comissão de Mortos e Desaparecidos a inclusão do nome de Anísio Teixeira na lista de mortos da ditadura militar e ainda que se prossigam com as investigações. C.f http://agenciabrasil.ebc.com.br/geral/noticia/2016-03/professor-diz-que-anisio-teixeirapode-ter-sido-morto-por-torturadores. 
${ }^{12}$ Artigos de periódicos, Capítulos de livros, discursos, folhetos, Livros, Prefácios e Posfácios, Textos de relha de livros, Textos inéditos, Trabalhos de Congressos e traduções. http://www.bvanisioteixeira.ufba.br/delivro.htm.

${ }^{13}$ Artigos de Periódicos, Capítulos de livros, Folhetos, Livros, Monografias e Teses e Trabalhos de Congressos.

${ }^{14}$ No Brasil, conforme Anísio Teixeira (1971) a escola primária passa por duas fases, na primeira, restringiase a classe média, era ainda para poucos, inspirada no modelo da Europa, sobretudo, da França, organizada "como um sistema de educação paralelo ao propriamente preparatório para a escola superior e formador da elite dominante" (TEIXEIRA, 1971, p. 126), reproduzia o dualismo educacional, visto que, completado os sete ou oito anos de estudos, o aluno encerrava sua vida escolar ou continuava nas escolas vocacionais. Até a década de 20 e 30, do século XX, a escola primária foi assim, marcando a sua segunda fase, nesse período em que buscava democratizá-la estendendo seu alcance para que todos pudessem beneficiar-se da escolar. Porém, ainda assim, com redução em sua duração e algumas distorções.

${ }^{15}$ Este documento divulgava as principais diretrizes de um programa de reconstrução educacional empreendido por um grupo de educadores, a saber: Lourenço Filho (Ceará/1922-23) e Fernando de Azevedo (DF/192730), Carneiro Leão (Pernanmbuco/1929) e outros que já haviam produzido reformas no ensino público do País.

${ }^{16}$ Subtítulo de um de seus escritos no livro Educação não é privilégio (TEIXEIRA, 1971p. 18).

${ }^{17}$ Palavra de origem inglesa, em português significa pelotão.

${ }^{18}$ Grifo do Autor.

${ }^{19}$ A cooperação fundada na divisão do trabalho adquire a sua forma clássica na manufatura. Predomina como forma caracteristica do progresso de repodução capitalista, durante o período propriamente dito a grosos modo, vai de meados do século XVI ao último terço do século XVIII (MARX, 1988, p. 386).

${ }^{20}$ Das 7:30 das manhã as 16:30min.

${ }^{21}$ Corresponde a uma sala de aula comum.

${ }^{22}$ Grifo Nosso.

${ }^{23}$ Grifo Nosso.

Recebido: Abril/2017.

Aprovado: Junho/2017. 